Volume, 13, n.2, Ano, 2017.

A TRANSEXUALIDADE EM QUESTÃO:

Problematizações nos contextos educacionais.

\author{
Renata Silva Pamplona ${ }^{1}$ \\ Nilson Fernandes Dinis ${ }^{2}$
}

RESUMO Este artigo tem como objetivo problematizar a categoria da transexualidade, a qual surge impulsionada pelos campos de saber-poder das ciências psiquiátricas e psicológicas. Tratase de um recorte de nossa pesquisa de doutorado, intitulada Pedagogias de gêneros em narrativas sobre transmasculinidades, desenvolvida no Programa de Pós-graduação em Educação/PPGE da Universidade Federal de São Carlos/ UFSCar. O objetivo central da pesquisa se estruturou na análise da categoria e experiências das transmasculinidades, nesse sentido, antes de analisarmos tal categoria, retomamos o percurso da produção da transexualidade. Especificamente, nos debruçamos a explorar o conceito de transexualidade enquanto um dispositivo tecnológico biopolítico, engendrado pela maquinaria do sistema patriarcal e heterossexual. Compreendemos ser fundamental que educadoras e educadores busquem problematizar o viés de produção das diferenças sexuais e de gênero, a exemplo da transexualidade, a fim de ampliar a possibilidade de exercerem práticas educativas plurais e não discriminatórias. Concluímos que as bases que estabelecem a categoria da transexualidade são invenções políticas, discursivas, históricas, culturais e sociais, realizadas intencionalmente por campos de saber específicos, os quais buscam manter o sistema patriarcal/heterocentrado.

Palavras-chave: Transexualidade. Gênero. Educação.

\title{
TRANSEXUALITY IN QUESTION:
}

Problematizations in the educational contexts.

ABSTRACT This article aims to problematize the category of transsexuality, which is driven by the knowledge-power fields of the psychiatric and psychological sciences. This is a section of our doctoral research, entitled Pedagogies of gender in narratives about

\footnotetext{
${ }^{1}$ Doutora em Educação pelo Programa de Pós-graduação em Educação/PPGE, Universidade Federal de São Carlos/ UFSCAR - Brasil. E-mail: renascersempre@ hotmail.com

${ }^{2}$ Professor associado no Departamento de Educação e no Programa de Pós-Graduação em Educação da Universidade Federal de São Carlos/ UFSCar. E-mail: ndinis@ufscar.br
} 


\section{ITTEERARIUS REFLECTIONIS}

Volume, 13, n.2, Ano, 2017.
REVISTA ELETRÔNICA

DA GRADUAÇÃ O/PÓS-GRADUAÇÃO EM EDUCAÇÃO

ISSN. 1807-9342

transmasculinities, developed in the Program of Post-graduation in Education / PPGE at Sao Carlos Federal University / UFSCar. The central objective of the research was structured in the analysis of the category and experiences of transmasculinities, in this sense, before analyzing this category, we returned to the path of transsexuality production. Specifically, we explored the concept of transsexuality as a biopolitical technological device, engendered by the machinery of the patriarchal and heterosexual system. We understand that it is fundamental that educators seek to problematize the bias of the production of sexual and gender differences, such as transsexuality, in order to increase the possibility of practicing plural and non-discriminatory educational practices. We conclude that the bases that establish the category of transsexuality are political, discursive, historical, cultural and social inventions, intentionally realized by specific fields of knowledge, which seek to maintain the patriarchal / heterocentric system.

Key-words: Transsexuality. Genre. Education

Esse artigo trata-se de um recorte do primeiro capítulo de nossa tese de doutorado, intitulada Pedagogias de gêneros em narrativas sobre transmasculinidades ${ }^{3}$. Nosso objetivo é realizar uma problematização da categoria transexualidade. Partimos do pressuposto que educadoras e educadores para realizarem suas práticas de ensino, de modo a incluir nos currículos as multiplicidades sexuais e identidades de gênero, em específico, as transexualidades ${ }^{4}$, necessitam alargar seus conhecimentos a respeito de tais temáticas e realidades. Nosso texto se lança nesse propósito, percorrendo o itinerário de produção da categoria das transexualidades.

Inicialmente, sublinhamos que as pessoas transexuais, do mesmo modo que travestis, intersexuais, dragqueens, dragkings, operam uma marca da diferença acentuada ao romperem as convenções sociais hegemônicas, presentes na cultura ocidental, no que se refere às atribuições tradicionais de sexo e de gênero.

Tais sujeitos transitam nos limites estabelecidos pelos preceitos de gênero, e produzem inquietude diante de sua plasticidade e volatilidade, impressa em seu corpo.

\footnotetext{
3 Pesquisa desenvolvida no Programa de Pós-graduação em Educação/PPGE da Universidade Federal de São Carlos/ UFSCar, no período de 2013-2017, com apoio do CNPq.

${ }^{4}$ Buscaremos incluir o termo no plural, por compreendermos que não existe apenas uma manifestação da transexualidade, mas múltiplas expressões.
} 


\section{TTMERARUS REFLECTIONIS}

Volume, 13, n.2, Ano, 2017.

ISSN. 1807-9342

Não raro ocasionam temor, dúvida e espanto, desencadeando a exclamação: é homem ou mulher?

Perante indagações dessa ordem, Berenice Bento argumenta que essas deveriam ser reelaboradas e expressas em termos como: "O que é um homem e uma mulher? Para que serve este lugar de gênero? Só é mulher quem tem um útero?” (BENTO, 2014, p. 49). De modo semelhante, podemos também indagar: só se é homem quem possui pênis? Como então qualificar os inúmeros homens que foram assignados homens em seu nascimento, mas amputaram seu órgão genital em decorrência de doenças ou acidentes? Esses deixam de ser homens?

Podemos falar em um homem ou mulher de verdade? Quem são e como saber? Falar em um homem e mulher de verdade só é possível a partir do eixo estrutural do sistema heterossexual, heterocentrado, fruto de uma concepção naturalizante que produz a mulher como passiva, frágil, submissa, e o homem como viril, másculo, ativo. No entanto, essa postulação dicotômica de atribuição dos gêneros e corpos sempre falha, pois, por mais refinada que seja a produção da feminilidade ou masculinidade, não as encontramos de forma cristalizada, essencializada e pura. Antes, há sempre um borrar de fronteiras entre o masculino/feminino, e vice-versa. Não é possível encontrar o masculino e o feminino original, já que esses são produzidos culturalmente e socialmente por normatizações de gênero perpassadas por dispositivos biopolíticos que legitimam e arquitetam as noções do ser homem e mulher.

Tais questões devem ser situadas dentro de um regime político e um sistema biopolítico complexo, as quais necessitam ser incansavelmente desconstruídas para se desmistificar o trabalho refinado que o sistema heterossexual processa ao produzir uma masculinidade e uma feminilidade naturalizadas e aprisionadas na lógica de um determinismo biológico.

Problematizaremos a categoria conceitual da transexualidade a partir desse lugar das engrenagens tecnológicas biopolíticas, sendo assim, nos lançaremos na tentativa de desmontar a maquinaria do sistema patriarcal e heterossexual, o qual também engendra a noção de transexualidade e a emoldura em um viés articulado às ciências médicas e psicológicas. Entendemos por tecnologia biopolítica o sentido dado por Beatriz Preciado, "Isto é, como um sistema complexo de estruturas reguladoras que controlam a relação 


\section{TTMEPARUS REFLECTIONIS}

Volume, 13, n.2, Ano, 2017.

entre os corpos, os instrumentos, as máquinas, os usos e os usuários" (PRECIADO, 2014, p.79).

Mais que definir a transexualidade a partir de um padrão fixo, salientamos a necessidade de buscar compreender as experiências transexuais em suas mais distintas nuances, em sua pluralidade e multiplicidade de apresentação e de produção realizada ao longo do curso histórico, e das muitas influências políticas, sociais e dos saberes e poderes vigentes.

As pessoas transexuais dissolvem a lógica causal entre sexo/gênero/orientação sexual e remexem os lugares fixos de compreensão do universo masculino e feminino, atribuídos de forma essencializada.

Entretanto, embora seja inviável e errôneo pensar a transexualidade em termos universais, optaremos inicialmente, e de forma abreviada, a compreender que a transexualidade se constitui pelo não reconhecimento do sujeito com seu sexo biológico assignado pelo nascimento. A pessoa se reconhece em um corpo estranho, distinto daquele que sente ser de fato seu gênero. Existe uma dimensão identitária e um conflito com as normatizações e regulações de gênero. Uma mulher trans é aquela que nasceu em um corpo biológico masculino e no entanto se identifica, ou se percebe, como mulher. Um homem trans é aquele que nasceu em um corpo biológico feminino, mas se identifica como homem, se reconhece como homem, seja, em sua personalidade, vestimentas, estrutura psíquica, entre outras. Contudo, salientamos não haver unanimidade em relação à nomeação da transexualidade masculina e feminina, conforme analisaremos posteriormente.

Tal redução não significa que as experiências e vivências das pessoas trans sejam universais, padronizadas, ou se encaixem em uma sintetização homogênea. Mais, essas são plurais, diversas. Cada pessoa trans, seja a/o transexual feminino ou masculino, é antes, ou, deveria ser, primordialmente pessoas humanas e, sendo assim, são constituídas e atravessadas por diferenças, multiplicidades e devires.

Não podemos encontrar uma redução discursiva para definir ou essencializar qualquer expressão identitária ou sexual, pois "Não existe o bissexual, a bissexual, assim como não existe a lésbica, o homossexual, a travesti, o/a transexual, a drag queen, existem sim, travestilidades, homossexualidades, lesbianidades, transexualidades e também bissexualidades" (PAMPLONA, 2012, p. 51). 


\section{ITTMEPARUUS \\ REFLECTIONIS}

Volume, 13, n.2, Ano, 2017.

Também deveria ser inexequível se falar em uma única vertente heterossexual, pois não localizamos o/a heterossexual verdadeiro, e sim formas e vivências da heterossexualidade, "Mesmo porque a heterossexualidade é uma tecnologia social e não uma origem natural fundadora" (PRECIADO, 2014, p. 30), embora tenha se normatizado, na modernidade ocidental, um padrão de heterossexualidade que é visto e desejado como o correto e autêntico. É fácil perceber qual o esboço de homem e mulher preenche o perfil modelo de casal heterossexual, ou seja, um casal monogâmico, de posses econômicas/consumidores, cristão, passíveis de reprodução, magros, com corpos saudáveis, sem deficiências e, preferivelmente, brancos.

Segundo Jorge Leite Júnior, o que sustenta a arquitetura da ideologia moderna de gênero, a qual fundamenta a heterossexualidade compulsória e também a heteronormatividade é “... o modelo de família heterossexual monogâmica reprodutiva burguesa, ainda que nuançada pelos avanços e mudanças conceituais e sociais característico das culturas ditas modernas” (LEITE JÚNIOR, 2008, p.114).

Portanto, é também, fundamentalmente, na esteira das discussões sobre gênero que transcorreremos pelos territórios conceituais da transexualidade, uma vez que os/as transexuais são sujeitos que transitam entre os sexos e os gêneros.

Teremos como referência central para nossa problematização, assim como para o resgate dos percursos e origem da categoria transexualidade, os estudos de Pierre-Henri Castel (2001), Jonathan Ned Katz (1996), Berenice Bento (2006, 2008), Jorge Leite Júnior (2008), Judith Butler (2010) e Beatriz Preciado (2014). Buscaremos transitar entre tais estudos com intuito de estabelecer possíveis conexões, às quais possam nos permitir problematizar a produção da transexualidade e de seus territórios traçados.

Assim, observamos que Judith Butler (2010), ao discorrer sobre os sentidos de gênero, evidencia que esses só se tornam possíveis mediante atos performativos, no sentido de que a ação do gênero requer uma performance repetida dos atos do que seja masculino ou feminino. Ou seja, só se aprende a viver em determinado núcleo de gênero, vivenciando repetidamente rituais próprios de cada gênero. Em outras palavras, os que foram designados em seu nascimento como meninos, não nascerão sabendo ser meninos, antes, aprenderão com os corpos, movimentos, falas, posturas dos sujeitos masculinos como deverá ser viver e assumir o gênero masculino. Sendo a mesma repetição performática aplicada às mulheres e ao gênero feminino, pois, para Butler: 
Volume, 13, n.2, Ano, 2017.

\begin{abstract}
Se os atributos e atos de gênero, as várias maneiras como o corpo mostra ou produz sua significação cultural, são performativos, então não há identidade preexistente pela qual um ato ou atributo possa ser medido; não haveria atos de gênero verdadeiros ou falsos, reais ou distorcidos, e a postulação de uma identidade de gênero verdadeira se revelaria uma ficção reguladora. $O$ fato de a realidade do gênero ser criada mediante performances sociais contínuas significa que as próprias noções de sexo essencial e de masculinidade e feminilidade verdadeiras ou permanentes também são constituídas, como parte da estratégia que oculta o caráter performativo do gênero e as possibilidades performativas de proliferação das configurações de gênero fora das estruturas restritivas da dominação masculinista e da heterossexualidade compulsória (BUTLER, 2010, p. 201).
\end{abstract}

Mesmo que não haja uma identidade preexistente, ou atos de gêneros verdadeiros ou falsos, Butler destaca a estratégia de ocultação dessa performance, fazendo assim parecer que os gêneros são naturais e essencializados. Portanto, todo sujeito que foge à atuação esperada e desejada pela dicotomia dos gêneros passa a ser visto como abjeto, estranho. Entre os quais, o/a transexual, pois constitui como afronta à prática legítima dos gêneros quando não consegue manter-se nos limites designados para o seu gênero no nascimento.

Leite Júnior realiza um importante destaque ao ponderar que a performatividade butleriana não se trata de uma escolha voluntária de um sujeito, pois "É uma repetição obrigatória das normas anteriores que constituem o sujeito, normas que não podem ser descartadas por vontade própria” (LEITE JÚNIOR, 2008, p.118).

Por sua vez, Beatriz Preciado dirá que "O gênero não é simplesmente performativo (isto é, um efeito das práticas culturais linguístico-discursivas) como desejaria Judith Butler” (PRECIADO, 2014, p. 29). O gênero está, em sua visão, para além da imitação.

O gênero é pura tecnologia, complexa, capaz de arquitetar, produzir, fabricar um sexo-prostético, ou uma tecnologia sexual e, sendo assim, tanto capaz de produzir e reiterar as dicotomias entre os corpos masculinos/femininos, como também capaz de implodir essas mesmas barreiras, por meio de resistências.

Sua plasticidade carnal desestabiliza a distinção entre o imitado e o imitador, entre a verdade e a representação da verdade, entre a referência e o referente, entre a natureza e o artifício, entre os órgãos sexuais e as práticas de sexo. $\mathrm{O}$ gênero poderia resultar em uma tecnologia sofisticada que fabrica corpos sexuais (PRECIADO, 2014, p. 29). 


\section{ITTMEPARUUS REFLECTIONIS}

Volume, 13, n.2, Ano, 2017.

Beatriz Preciado analisará, ainda, que é justamente essa produção sexo-prostético que assegurará aos gêneros masculinos e femininos sua naturalização. E toda falha constituinte da máquina heterossexual, vista pela aproximação imperfeita do irreal masculino e feminino “... deve se renaturalizar em benefício do sistema, e todo acidente sistemático (homossexualidade, bissexualidade, transexualidade...) deve operar como exceção perversa que confirma a regra da natureza" (PRECIADO, 2014, p. 30).

Percebemos nessa refinada análise, que a transexualidade, assim como expressões não heterossexuais, é tida como desvio, erro, acidente, mas, ao mesmo tempo, necessária para garantir e reafirmar a permanência das dicotomias de gêneros e da heterossexualidade.

A estratégia de utilização do outro, dito como o estranho, bizarro, anormal, portanto, indigno e abjeto, é recorrente na história da sexualidade para legitimar o dito normal, correto, padrão, aceitável, desejável.

O pesquisador Jonathan Ned Katz (1996), em A invenção da heterossexualidade, realiza uma desconstrução do processo de naturalização da sexualidade tida como normal, nomeadamente, a heterossexualidade. $\mathrm{O}$ termo heterossexual "... teria sido criado por volta de 1892, ou seja, depois do termo 'homossexual', e designava, em um primeiro momento, o amor patológico e desmedido por pessoa do sexo oposto, só posteriormente adquirindo o sentido de norma e de referência para a sexualidade" (PAMPLONA; DINIS, 2013, p. 6).

De forma instigante, o autor quebra aquilo que nos parece óbvio, para mostrar que não existe nada de evidente, e sim de produções precisas. Por exemplo, questiona o motivo de falarmos sobre a travestilidade, quando não questionamos o fato de vestirmos roupas designadas para nosso próprio sexo. Assim, poderíamos questionar o porquê de uma mulher usar saias, vestidos, batons, saltos. Falamos sobre raça, mas pouco sobre ser da raça branca, e menos ainda problematizamos a normalidade e naturalidade produzida em torno da branquitude ${ }^{5}$. Falamos muito sobre a história das mulheres e bem menos

\footnotetext{
${ }^{5}$ Para entender a branquitude, é importante compreender a forma como se constroem as estruturas concretas de poder em que as desigualdades raciais se ancoram. Faz-se necessário entender as formas de poder da branquitude, onde ela realmente produz efeitos e materialidades, estabelece e gera efeitos de verdade [...] A branquitude está relacionada a situações de privilégio e de poder, as quais conferem vantagens, prestígio e estabelecem padrões normativos a serem seguidos pelo Outro não branco. E desse modo, a escola privilegia de forma icônica um grupo racial branco em detrimento do negro. (SOUZA, 2016, p. 115-116)
} 


\title{
ITTMEPARUUS REFLECTIONIS
}

Volume, 13, n.2, Ano, 2017.

sobre a dos homens, a qual ganha evidência apenas nos últimos anos, com os estudos sobre as masculinidades.

E, designadamente, destacamos as colocações do pesquisador em relação à transexualidade, quando afirma:

\begin{abstract}
Falamos sobre Transexualismo (dando-lhe esse nome) problemático, a sensação de ser do sexo oposto, o desejo de ter o corpo do outro sexo. Não falamos muito sobre a sensação de ser do próprio sexo (ou damos a isso um nome) - o sexo que acreditamos ser o nosso, o que a maioria de nós deseja conservar. Mas o fato de nos sentirmos relativamente bem com o nosso sexo e o forte desejo de manter a nossa integridade sexual não indicam algo que precisa ser explicado, tanto quanto o transexualismo? (KATZ, 1996, p. 26).
\end{abstract}

Katz, de maneira perspicaz, levanta questionamentos que para muitas pessoas seriam impensáveis, pois esses desestabilizam a maquinaria do sistema sexo/gênero ao fazer colocações simples. Ou seja, não falamos muito sobre a sensação de ser do sexo que somos. E será que somos mesmo do sexo que acreditamos ser o nosso? Ou antes, podemos fazer tal proposição? O fato de termos uma genitália considerada de determinado sexo é fator mais importante que outros em nosso comportamento, corpo, afeto, emoção, pensamento para designar nosso gênero? Por que é normal nos sentirmos bem com nosso sexo de nascimento? Não deveríamos questionar nosso sexo, nosso gênero, como muitas vezes questionamos o nome que nos foi dado no nascimento? Segundo Katz, a não ser quando somos pressionados por vozes fortes e insistentes, não temos o costume de dar nome "... à norma, ao normal e ao processo social de normalização, muito menos os consideramos desconcertantes, objetos de estudo. A análise do anormal, do diferente e do outro, das culturas da minoria, aparentemente tem despertado um interesse muito maior" (ibid., p. 27).

Se tais indagações podem parecer absurdas, não são quando se trata da transexualidade, pois aí sim, parece ser normal indagar qual razão leva uma pessoa a se sentir em um corpo errado, desejar ser de outro gênero, diferente daquele que lhe foi atribuído no nascimento.

De acordo com Berenice Bento "A transexualidade é uma das múltiplas expressões identitárias que emergiram como uma resposta inevitável a um sistema que organiza a vida social fundamentada na produção de sujeitos 'normais/anormais' e que localiza a verdade das identidades em estruturas corporais" (BENTO, 2008, p. 24-25). 


\section{ITTMEPARUUS \\ REFLECTIONIS}

Volume, 13, n.2, Ano, 2017.

Seria um equívoco, conforme aponta a pesquisadora Bento (2008), proceder a uma investigação sobre a trajetória da transexualidade fora da perspectiva histórica em que as identidades passam a ser prisioneiras do corpo e as condutas tornam-se medicalizadas.

Para que a transexualidade se tornasse compreensível, segundo a explicação da verdade dos gêneros centrada na diferenciação dos corpos masculinos e femininos, foi necessário um embate com a interpretação do isomorfismo, segundo a qual não havia diferenciações entre um corpo feminino e outro masculino. A partir da concepção do isomorfismo "Até meados do século XVII, os anatomistas trabalhavam com a convenção de que existia apenas um corpo e pelo menos dois gêneros...” (BENTO, 2008, p. 24).

Somente a partir dos séculos XVIII e XIX os discursos e saberes começam a se arquitetarem e questionarem uma nova convenção social do que é ser homem e mulher, ou seja, o dimorfismo. Assim, "Por volta da segunda metade do século XVIII, as diferenças anatômicas e fisiológicas visíveis entre os sexos não eram consideradas, até que se tornou politicamente importante diferenciar biologicamente homens e mulheres, mediante o uso do discurso científico" (BENTO, 2008, p. 25).

Em decorrência dessa diferenciação sexual entre masculinidade e feminilidade passou-se a nomear aquelas pessoas que borravam a clareza das distinções dicotômicas do feminino e masculino.

A denominação transexual mais recorrente e ainda utilizada na contemporaneidade é um termo cunhado internacionalmente no século $\mathrm{XX}$, a partir da década de 1950, pelo saber médico-psiquiátrico, o qual compreende a transexualidade como um transtorno de comportamento. Nesse viés biologizante é inevitável a associação da transexualidade à doença mental e a uma dimensão patologizante, sendo assim, nomeada de transexualismo. O saber médico e das ciências psicológicas, da mesma forma que já havia patologizado a homossexualidade, irá empreender o mesmo processo com a transexualidade. Assim, “Transexualismo' é a nomenclatura oficial para definir as pessoas que vivem uma contradição entre corpo e subjetividade. O sufixo 'ismo' é denotativo de condutas sexuais perversas, como, por exemplo, 'homossexualismo"”. (BENTO, 2006, p. 44).

Anteriormente, em 1910, o sexólogo Magnus Hirschfeld cunha em seu livro Die Tranvestiten, o termo transexual e transexual psíquico. É o primeiro livro onde aparecerá tal designação, como destaca o historiador Pierre-Henri Castel (2001). 
Volume, 13, n.2, Ano, 2017.

Como se vê no título, não se trata de separar o transexualismo (a palavra figura, de resto, inserida na expressão "transexual psíquico") do conjunto das perversões, mas, sobretudo, de um lado, de separar as formas de homossexualidade, e de outro, de estabelecer que o transvestismo não é uma prática especificamente homossexual, em via de destruir a homogeneidade aparente da categoria de "atos contra a natureza" (CASTEL, 2001, p. 81).

Novamente o termo transexual é utilizado em 1949, por Cauldwell, conforme aponta Bento (2006), quando esse “... publicou um estudo de caso de um transexual masculino. Nesse trabalho são esboçadas algumas características que viriam a ser consideradas exclusivas dos/as transexuais. Até então, não havia uma nítida separação entre transexuais, travestis e homossexuais" (BENTO, 2006, p. 40).

Intensificam-se, assim, a partir de 1950, as publicações "que registram e defendem a especificidade do 'fenômeno transexual'. Essas reflexões podem ser consideradas o início da construção do 'dispositivo da transexualidade"” (idem). É importante destacar a analogia realizada pela pesquisadora Berenice Bento, a partir da qual toma a noção de dispositivo da sexualidade para se referir ao dispositivo da transexualidade. Relembramos aquilo que Foucault compreende por dispositivo da sexualidade:

\begin{abstract}
A sexualidade é o nome que se pode dar a um dispositivo histórico: não à realidade subterrânea que se aprende com dificuldade, mas à grande rede da superfície em que a estimulação dos corpos, a intensificação dos prazeres, a incitação ao discurso, a formação dos conhecimentos, o reforço dos controles e das resistências, encadeiam-se uns aos outros, segundo algumas grandes estratégias de saber e poder (FOUCAULT, 2010, p. 116-117).
\end{abstract}

Compreender a transexualidade como um dispositivo é bastante pertinente, dada a existência de uma proliferação de discursos circulando em torno da figura do/da transexual, assim como a manipulação dos corpos transexuais, a exemplo das intervenções cirúrgicas que irão ganhar notoriedade nesse momento, e reforçar a consolidação desse dispositivo. O que é possível perceber perante:

A articulação entre os discursos teóricos e as práticas reguladoras dos corpos ao longo das décadas de 1960 e 1970 ganhou visibilidade com o surgimento de associações internacionais, que se organizam para produzir um conhecimento voltado à transexualidade e para discutir os mecanismos de construção do diagnóstico diferenciado de gays, lésbicas e travestis. Nota-se que a prática e a teoria caminham juntas. Ao mesmo tempo em que se produz um saber específico, são propostos modelos apropriados para o "tratamento" (BENTO, 2006, p. 40). 


\section{ITMERARUS REFLECTOONIS}

Volume, 13, n.2, Ano, 2017.

ISSN. 1807-9342

Por sua vez, Harry Benjamin, médico endocrinologista alemão radicado nos Estados Unidos, é considerado o pai da transexualidade após a publicação de seu livro $O$ fenômeno transexual, em 1966, e a retomada do termo transexual utilizado por Cauldwell. Será um personagem relevante na gama do saber específico para a produção do dispositivo da transexualidade. Com influências de sua obra, a condição transexual passa a ser reconhecida e submetida a tratamento médico, passando a ser admitida nas nosografias psiquiátricas, de acordo com Castel (2001).

Para Harry Benjamim, a gênese da transexualidade se associa a uma ordem biológica, e o dilema em que vivem as pessoas transexuais só pode ser minimizado mediante a cirurgia de transgenitalização. Segundo Bento (2008), o endocrinologista Benjamim forneceu as bases para o diagnóstico do "verdadeiro transexual". Diagnóstico que só poderá ser realizado pelo saber médico-psiquiátrico e pelo refinado nascente dispositivo da transexualidade.

Benjamim, como mostra Bento (2006), ao propor a cirurgia como única alternativa terapêutica possível para o tratamento dos/das transexuais, empreenderá uma forte oposição aos profissionais da saúde mental, particularmente aos psicanalistas, uma vez que esses eram radicalmente contrários às intervenções corporais como alternativas terapêuticas, pois as consideravam como mutilações.

A primeira intervenção de redesignação sexual é datada de 1921, conforme afirma Castel (2001). O cirurgião Felix Abraham, aluno de Eugen Steinach, opera clandestinamente Rudolf, o primeiro transexual redefinido.

O procedimento cirúrgico de redesignação sexual, nomeadamente, a vaginoplastia, é um procedimento de domínio médico desde a segunda metade do século XIX, conforme destaca Castel (2001). Já a faloplastia, tem o início de seu aperfeiçoamento com o médico Harold Gillies, considerado:

\footnotetext{
... um dos pais da cirurgia plástica, virtuose de sua profissão, que a havia experimentado em 1917 em soldados mutilados. Gillies, ao qual se dirigiram após 1919 os intersexuais, e que redigiu um manual de cirurgia urogenital sobre esses pacientes, opera também alguns transexuais. Ele parece ter praticado a primeira faloplastia em Laura Dillon, que se tornou Michael, primeira militante do "direito moral" à mudança de sexo. Ele os considera todos, como Abraham, e mesmo Daniel Stürup (que fará parte da equipe encarregada de Goerge Jorgensen em 1952) como homossexuais e transvestistas (CASTEL, 2001, p. 85).
} 
Volume, 13, n.2, Ano, 2017.

Embora exista a neofaloplastia desde 1917, no Brasil apenas em 2010 o Conselho

Federal de Medicina regulamentou o processo transexualizador para transexuais masculinos, o qual consiste na remoção do útero, ovário e das mamas. No entanto, a neofaloplastia, ou seja, a construção do pênis segue ainda em caráter experimental, conforme atesta Camila de Jesus Mello Gonçalves:

A técnica cirúrgica encontra limites em si mesma, persistindo dificuldades para a obtenção de bom resultado tanto no aspecto estético quanto no funcional, das neofaloplastias, mesmo nos casos com boa indicação de transformação do fenótipo feminino para o masculino (décimo primeiro Considerando da Resolução CFM 1.955/10). Em razão do estado da técnica, neste caso, a autorização para a realização da cirurgia ainda é dada somente a título experimental (Resolução CFM 1.995/10, art. 2º). (GONÇALVES, 2014, p. 176).

É interessante observar como em uma época histórica de grandes avanços na área das tecnociências, biotecnologias, tecnologias da informação atreladas à medicina, robótica, e as constantes invenções de máquinas, terapias gênica e celular, implantes cerebrais, entre outras inúmeras técnicas de grandiosa sofisticação e eficácia médica, coexiste um lento avanço na intervenção cirúrgica da vaginoplastia e, especialmente da faloplastia. Entretanto, tal lentidão contrastada com os avanços da medicina nos primeiros anos do século XXI, não ocorre por simples acaso, antes, existe uma intencionalidade política de manutenção e estabilização das categorias heteronormativas de sexo e gênero, como bem delineia Beatriz Preciado.

\footnotetext{
A sofisticação da maior parte dos ramos da medicina terapêutica e da cibernética (xenotransplantes, próteses cibernéticas visuais e auditivas etc.) contrasta com o subdesenvolvimento das tecnologias que permitem modificar os órgãos (faloplastia, vaginoplastia...) e as práticas sexuais (tomemos, por exemplo, a escassa evolução do preservativo nos últimos dois mil anos). A meta das atuais biotecnologias é a estabilização das categorias heteronormativas de sexo e de gênero (que vai da erradicação das anormalidades sexuais, consideradas como monstruosidades no nascimento ou antes do nascimento, às operações no caso de pessoas transexuais) (PRECIADO, 2014, p. 40-41).
}

Pioneiro nas intervenções cirúrgicas para a mudança ou definição de um único sexo, junto ao nome de Harry Benjamim, é o nome John Money, que irá se dedicar aos estudos da intersexualidade e as diferenças do masculino/feminino. De acordo com Bento (2006), o psicólogo e professor de psicopediatria, John Money, nascido na Nova Zelândia, vai para os Estados unidos para estudar casos de crianças intersexuais, na primeira clínica 


\section{ITTMEPARUUS \\ REFLECTIONIS}

Volume, 13, n.2, Ano, 2017.

ISSN. 1807-9342

especializada em identidade de gênero, no hospital universitário de John Hopkins, na cidade de Baltimore. Nesse local, elabora e utiliza pela primeira vez, em 1955, suas primeiras teses sobre o conceito de gênero, apoiado na teoria dos papéis sociais do sociólogo Tàlcott Parsons, remetendo assim às diferenças sexuais ao aprendizado sociocultural dos papéis de masculinidade e feminilidade.

Assim, "A conclusão à qual chegava Money em 1995 não podia ser, aparentemente, mais revolucionária: o gênero e a identidade sexual são modificáveis até a idade de 18 meses" (PRECIADO, 2014, p.132). Entretanto, sem abandonar o crivo biológico, responsável por coroar a supremacia da genitália como aquela que permitirá atribuir o sexo correspondente do sujeito, ou seja, se masculino, feminino ou intersexual. Se intersexuais, os bebês deverão se submeter às cirurgias corretivas para escolha do sexo mais adequado, dependendo da preponderância de cada genitália e seu melhor encaixe às normas do sistema heterocentrado.

Leite Júnior (2008), em análise dos conceitos de Butler, delineia que a filósofa considera a tese de Money revolucionária ao afirmar que o comportamento de gênero não é inato ao funcionamento de gênero. Entretanto, Butler ainda considera que o psicólogo Money “... procurava manter a tradicional inteligibilidade de gênero, ou seja, que as pessoas com pênis deveriam ser 'masculinas' e sentir atração afetivo-sexual por mulheres e vice-versa" (LEITE JÚNIOR, 2008, p. 143). Assim, o saber médico e as intervenções cirúrgicas realizadas com crianças com algum nível de intersexualidade “... visavam então manter a lógica heteronormativa: 'construir' vaginas para meninas que deveriam ter uma vida sexual com meninos e 'pênis' para garotos que seriam educados a desejar garotas" (LEITE JÚNIOR, 2008, p. 143).

Por sua vez Preciado (2014), em uma análise detalhada, destaca a importância e autoridade de Money nos anos cinquenta, para a atribuição sexual do recém-nascido e de reconstrução sexual. De forma sarcástica, afirma que indubitavelmente podemos considerar que "Money makes sex" (PRECIADO, 2014, p.133), ou seja, era de fato um fabricador de sexos ao ter em suas mãos um saber-poder capaz de produzir um sexo tido como o mais apropriado em cada circunstância, ou, em cada genitália indefinida. A eficácia de seu modelo resulta “... da combinação estratégica de duas linguagens, de duas epistemologias que serão utilizadas para descrever o corpo: a análise cromossômica e o juízo estético" (PRECIADO, 2014, p.133). 


\section{ITIMERARUIS \\ REFLECTIONIS}

Volume, 13, n.2, Ano, 2017.

No modelo de Money, os corpos intersexuais, assim considerados por um critério de exploração visual, serão submetidos a um longo processo de operações genitais que transcorreram até a pré-adolescência. É minuciosa e bastante intencionada a lista de definições para a atribuição de sexo. O tratamento observará de início a combinação cromossômica, e outras linguagens específicas para a atribuição sexual, como: “Clitopênis, micropênis, microfalo, pênis-clitóris", segundo mostra Preciado (2014, p. 134).

Em sua análise, a filósofa busca argumentar como todo o processo de atribuição sexual se dá nos parâmetros de respaldo do sistema sexo/gênero heterocentrado. Ou seja, o recém-nascido considerado geneticamente feminino $(\mathrm{XX})$ deverá suprimir qualquer vestígio de um pênis, ainda que lhe custe a mutilação do clitóris, e mais tarde se fará a construção do canal vaginal. Nesse caso, é inegável que a preocupação central é que essa vagina seja capaz de receber um pênis no coito heterossexual, sem ao menos considerar que futuramente essas meninas intersexuais pudessem ser "sapas", segundo observa Preciado (2014).

Em relação à atribuição sexual masculina, quando a criança é XY, a preocupação é com o "tecido fálico", a possibilidade de aumento do "microfalo" ou do "micropênis", com os critérios de "longitude", de "tamanho" e de "aparência normal" dos genitais, ou, como bem salienta Preciado, a preocupação é com o resultado da "política do centímetro" (2014, p.140). Semelhante à atribuição feminina, a inquietação é que o indivíduo possa ser capaz de ter relações heterossexuais genitais.

Caso houvesse para Money e seus colaboradores, qualquer incerteza em relação ao tamanho e desenvoltura futura do pênis que pudessem gerar conflitos em relação à identidade, seria preferível realizar o procedimento de vaginoplastia. $\mathrm{O}$ que acarretava $\mathrm{o}$ fato de frequentemente a maior parte dos bebês intersexuais XX ou XY serem atribuídos ao gênero feminino. O que nos faz concordar que "Para Money, então 'o masculino' não está definido por um critério genético (possuir um cromossomo y e um x) ou pela produção de esperma, mas por um critério estético, o fato de ter uma protuberância pélvica 'do tamanho apropriado"” (PRECIADO, 2014, p.140).

As postulações de Money embora tragam algum vislumbre para a inovação em relação ao aprendizado social dos gêneros, recua em defesa da sociedade heterocentrada quando visa à extinção da ambiguidade dos sexos por meio das intervenções cirúrgicas 
Volume, 13, n.2, Ano, 2017.

de adequação do sexo/gênero. Ou antes, teme as consequências políticas e sociais de uma identidade de gênero ambígua e fluida, como também observou Preciado em relação às teses de Money:

\begin{abstract}
Se Money afirma que a identidade sexo/gênero é modificável até aproximadamente os 18 meses (embora os tratamentos hormonais e cirúrgicos prossigam inclusive depois da puberdade) não é porque não existe a possibilidade de mudança depois dessa idade (como as operações de mudança de sexo e de reatribuição nas pessoas transexuais suficientemente provam), mas sim porque o discurso médico não pode lidar com as consequências políticas e sociais da ambiguidade ou da fluidez sexual para além da tenra infância. Por isso, segundo Money, o sexo deve ser atribuído o mais rápido possível, o que com frequência quer dizer imediatamente, à primeira vista. E isso, de maneira decisiva e irreversível (PRECIADO, 2014, p. 142).
\end{abstract}

Após percorrermos por algumas leituras e contribuições teóricas a respeito do modelo de Money referente às designações de gênero para bebês intersexuais, gostaríamos de destacar sua influência na elaboração do dispositivo da transexualidade, pois, a transexualidade passa a ser considerada como disforia de gênero.

O termo disforia de gênero foi cunhado por John Money e Norman Fisk em 1973, após o primeiro congresso da Harry Benjamin Association, realizado em Londres em 1969, o qual modificou seu nome em 1977 para Harry Benjamin International Gender Dysphoria Association (HBIGDA), e consolidou-se como referência para o tratamento de pessoas transexuais.

A designação disforia de gênero traz em seu bojo duas vertentes de produção do saber a respeito da transexualidade. São elas: “... o desenvolvimento de teorias sobre o funcionamento endocrinológico do corpo e as teorias que destacaram o papel da educação na formação da identidade de gênero" (BENTO, 2006, p. 42). Tais concepções serão centrais para a constituição do dispositivo da transexualidade e de seus desdobramentos, como a forte ênfase dada a seu tratamento, já que a vertente biológica e médicopsiquiátrica obtiveram maior refinamento ao operar as disputas de saber-poder. Sendo causal a noção de que a disforia de gênero nada mais era que distúrbio, ou transtorno de gênero, portanto, anomalia.

De acordo com Castel, a transexualidade “... figura hoje no manual-diagnóstico publicado pela Associação Americana de Psiquiatria (DSM 4), não sob o título de 'transexualismo', mas como 'distúrbio de identidade de gênero"” (CASTEL, 2001, p. 7778). 


\section{ITTMEPARUS \\ REFLECTIONIS}

Volume, 13, n.2, Ano, 2017.

ISSN. 1807-9342

Tal acontecimento apresenta consequências importantes ainda na atualidade. Por um lado se constitui como uma defesa em relação às pessoas transexuais, e seu grande anseio de correção de um corpo inadequado às aspirações do gênero identificado. Por outro, constitui uma armadilha ao reafirmar um modelo dicotômico e patológico de gênero, em um sistema heterocentrado.

Embora afirmar que uma pessoa é ou não transexual incida em uma impossibilidade objetiva, não se caracterizou como impedimento para que a refinada maquinaria das ciências médicas e das ciências $\mathrm{psi}^{6}$ sofisticassem procedimentos para realizar tal determinação. Para Berenice Bento "O que assusta é perceber que tão pouco saber, dito científico, gerou tanto poder" (BENTO, 2008, p. 119).

As pessoas que desejam se submeter ao processo transexualizador deverão aceitar, sem quase nenhuma possibilidade de questionamento, às exigências dos centros médicos responsáveis, e o rol de procedimentos exigidos para a redesignação sexual. "Os protocolos irão concretizar essas obrigatoriedades quanto ao tempo de terapia, à terapia hormonal, ao teste de vida real, aos testes de personalidade, além dos exames de rotina" (BENTO, 2006, p. 48). Somente depois de passar pelo menos dois anos por esse humilhante, exaustivo, e porque não desumano processo, o/a transexual, se conseguir cumprir todas as etapas e exigências instituídas, estará apto/a ao processo transexualizador e à cirurgia de transgenitalização.

Existe uma normatização oficial/internacional/universal que regulamenta por meio de documentos a orientação do diagnóstico e tratamento da transexualidade. "A HBIGDA publica regularmente as Normas de Tratamento (State of Care ou SOC) que orientam profissionais que trabalham com transexualidade em todo o mundo. Atualmente o SOC está em sua 6 $6^{\mathrm{a}}$ versão" (BENTO, 2008, p. 97).

Outros dois documentos são reconhecidos internacionalmente no tratamento da transexualidade, o Manual de Diagnóstico e Estatísticas de Distúrbios Mentais (DSM- 4) da Associação Psiquiátrica Americana (APA), e o Código Internacional de Doenças (10 Versão), ou CID-10.

Bento (2008) esclarece que esses documentos foram construídos a partir da perspectiva da transexualidade como doença, sendo assim, como doentes, as pessoas

\footnotetext{
${ }^{6}$ Termo designado para nomear as ciências: psicologia, psiquiatria, psicanálise.
} 
Volume, 13, n.2, Ano, 2017.

apresentam características comuns e universais, independente de diferenças culturais, econômicas ou sociais. Entretanto, existem algumas particularidades em cada documento, tais como:

\begin{abstract}
Para o SOC, 'o transexual de verdade' tem como única alternativa para resolver seus 'transtornos' ou 'disforias', as cirurgias de transgenitalização. Já no DSMIV, a questão da cirurgia é apenas tangenciada, visto que sua preocupação principal está em apontar as manifestações do 'transtorno' na infância, adolescência e fase adulta. O CID-10 é o documento mais objetivo: apresenta as características gerais e o código que deve estar presente em todos os diagnósticos referentes 'ao transexualismo' (BENTO, 2008, p. 99).
\end{abstract}

A/o transexual só será assim diagnosticada/o, como uma/um transexual verdadeira/o, primeiramente se aceitar ser nomeada/o como doente, possuidora/o de um transtorno de gênero e, posteriormente, se lutar para obter um laudo que comprove ser um/uma transexual verdadeiro/a. O qual na sua impossibilidade objetiva de se realizar, ou seja, de atestar a veracidade da transexualidade, se fará a partir de um referencial normativo passível de nomear e designar o que seja homem e mulher, segundo as normas dicotômicas de gêneros. A respeito dessa inexistência objetiva da nomeação da transexualidade, Bento afirma que:

Diante da transexualidade, a suposta objetividade dos exames clínicos não faz nenhuma diferença. Nessa experiência o saber médico não pode justificar os 'transtornos' por nenhuma disfunção biológica, como aparentemente se argumenta com o caso dos intersexos que devem se submeter às cirurgias para retirar-lhes a ambiguidade estética dos genitais, conformando-os com os corpos-sexuados hegemônicos (BENTO, 2008, p. 118).

Portanto, o transexual não deixa de recair, para além da perspectiva patologizante de possuir um transtorno mental, no essencialismo da heterossexualidade, que postula: ou se possui pênis ou vagina, ou se é homem ou mulher, ou se é feminino ou masculino. As indefinições e ambiguidades são temidas e devem ser corrigidas para a adequação mais precisa, seguindo o mesmo modelo defendido e postulado pelo psicólogo John Money.

Em outras palavras, o diagnóstico que define se o sujeito é ou não transexual se fará em decorrência do entendimento do que seja homem e do que seja mulher. Entretanto, como já discorremos, falar em uma mulher e homens originais, verdadeiros, também não é uma tarefa possível, ainda que na modernidade tardia algumas postulações tenham sido realizadas nessa direção. 


\section{ITTMEPARUIS REFLECTIONIS}

Volume, 13, n.2, Ano, 2017.

A esse respeito Katz afirma que na América, "No início do século XIX, foram definidos ideais particulares de masculinidade e feminilidade, o que criou um culto do homem e da mulher de verdade" (KATZ, 1996, p. 55). Tais ideais pautavam-se pela defesa do amor verdadeiro entre um homem e uma mulher e de suas aspirações como classe média, em especial com a reprodução. Assim, "O verdadeiro amor era um sistema hierárquico dominado por um sentimento espiritual suficientemente forte para justificar o casamento, a reprodução e a sensualidade, que de outra forma era pecaminosa" (KATZ, 1996, p. 56). O corpo estava a serviço do amor verdadeiro e os órgãos (vagina e pênis) eram apenas ferramentas para a procriação, e não instrumentos de prazer. Para Katz:

\footnotetext{
Naquele tempo, considerava-se que o corpo humano constituía diretamente o homem e a mulher de verdade, e os seus sentimentos. Não era feita qualquer distinção entre o sexo propiciado biologicamente e a masculinidade e feminilidade construídas socialmente. Sob o domínio do verdadeiro amor, o corpo humano era considerado o meio de expressão. De acordo com a norma de reprodução do início do século XIX (como na Nova Inglaterra primitiva), o pênis e a vagina eram meios de procriação - órgãos reprodutores - não partes prazerosas. Somente depois do casamento podiam unir-se no amor. (idem).
}

O que estava em jogo era a garantia do amor indissolúvel entre um homem e uma mulher e sua capacidade reprodutiva para perpetuação da família de classe média, especialmente para se distinguir da classe alta, considerada promíscua, e da classe baixa, tida como vulgar e animalesca. Essa necessidade de se diferenciar como classe e fixar seus valores permite perceber que "A criação da classe média e a invenção da heterossexualidade caminharam de mãos dadas" (ibid., p. 52).

A capacidade reprodutiva era o instrumento de medida para saber se um homem e uma mulher eram homem e mulher de verdade, pois "O local onde o amor era consumado - de procriação - era o santuário do verdadeiro amor do século XIX, o lar do homem e da mulher de verdade" (ibid., p. 56). No entanto, é preciso salientar que não há nesse momento uma distinção entre amor romântico/apaixonado e a sensualidade, ou seu caráter imoral enquanto desejo sexual. Assim como ainda não temos a invenção da heterossexualidade, e tampouco a invenção da homossexualidade, que é criada primeiramente como modelo daquilo que é o ruim, abjeto e monstruoso, para então se criar o que o bom, normal e aceitável, ou seja, a heterossexualidade. Mas, já temos a centralidade e importância dada à vagina e ao pênis como ferramentas centrais na união/coito de um homem e uma mulher. Era potencialmente o ato sexual que "... 


\title{
TTMEPARUS REFLECTIONIS
}

Volume, 13, n.2, Ano, 2017.

distinguia a mulher de verdade, virtuosa, da desonrada. A abstenção do ato sexual era o teste final do valor do homem de verdade, de seu status de cavalheiro cristão e bemeducado" (KATZ, 1996, p. 58).

Essa importância dada ao ato sexual com a obrigatoriedade da presença de uma vagina e de um pênis será fundamental para a emergência das categorias homossexualidade e heterossexualidade, uma vez que:

\begin{abstract}
O heterossexual e o homossexual não surgiram do nada em 1892. Aquelas duas categorias eróticas de sexo diferenciado estavam em formação desde 1860. Na Alemanha, na Inglaterra, na França, na Itália e na América do final do século XIX, nossa ideia moderna e historicamente específica do heterossexual começou a ser construída; a experiência de uma devida luxúria de sexo diferente da classe média começou a ser publicamente nomeada e documentada (KATZ, 1996, p. 62).
\end{abstract}

Falar em uma mulher e homem de verdade ainda não quer dizer falar em heterossexualidade, mas certamente constrói suas bases, e contribui para forjar sua invenção. Assim como contribui igualmente para criar a fantasia da existência de um homem e de uma mulher originais, autênticos/as, verdadeiros/as, universais, e, portanto, modelo para todas as culturas e épocas históricas, independentemente de suas particularidades.

Katz, ao realizar uma genealogia da invenção da heterossexualidade, objetiva justamente desconstruir o postulado de sua normalização como prática legítima e superior, por reunir em um mesmo espaço a capacidade reprodutiva e o deleite erótico. Assim, sugere que a heterossexualidade “... não é análoga ao ato sexual reprodutivo do sexo; não é o mesmo que as diferenças sexuais; não é igual ao erotismo de mulheres e homens" (KATZ, 1996, p. 25). Antes, assevera que a heterossexualidade não é universal, pois se trata de um arranjo histórico particular dos sexos e de seus prazeres. Ou, em outras palavras, "Mesmo porque a heterossexualidade é uma tecnologia social e não uma origem natural fundadora" (PRECIADO, 2014, p. 30).

Katz argumenta que no início da invenção da categoria heterossexual o sujeito heterossexual não era identificado e conhecido pela prática do sexo hoje considerado normal. Era sim, visto como pervertido, devido seu apetite sexual aflorado, não inclinado para a exclusividade da procriação. Pessoas heterossexuais eram condenadas quando se desviam de suas obrigações reprodutivas. De tal modo "Sob a influência do velho padrão 
Volume, 13, n.2, Ano, 2017.

reprodutivo, o novo termo heterossexual a princípio nem sempre significou o normal e bom" (KATZ, 1996, p. 31).

Ironicamente, a heterossexualidade que nasce pela contestação do ato reprodutivo, mais tarde se reportará à própria naturalização da reprodução para rechaçar outras configurações sexuais, como as homossexualidades, lesbianidades, transexualidades. Decorre supor que “... a heterossexualidade se situa na esfera de natureza, biologia, hormônios e genes - uma questão de fato fisiológico, uma verdade da carne. Apenas secretamente ela é um valor e uma norma, uma questão de moralidade e gosto, de política e poder" (KATZ, 1996, p. 51).

A heterossexualidade passa a se firmar como fato consolidado no final do século XIX, assim como ser homem e mulher tornou-se sinônimo e atestado da prática heterossexual, por meio do encontro harmonioso de seus corpos. Os gêneros e práticas sexuais que ameaçavam essa normalidade heterossexual passam a ser tidos como monstruosos e indesejáveis, devendo ser tratados, convertidos e curados, buscando eliminar qualquer barreira para a identificação do homem e mulher verdadeiros, carimbos da heterossexualidade.

A respeito da indissociabilidade entre homossexualidade e heterossexualidade Miguel Vale de Almeida, considera que:

O que distingue a emergência do 'homossexual' na segunda metade do século XIX é o facto de que então se tomou inseparável e literalmente incompreensível sem o seu gêmeo 'normal', 'o heterossexual'. Assim, a heterossexualidade é também uma construção cujo significado depende de modelos culturais cambiáveis. Ora, nos finais do século XX, tanto a hetero quanto a homossexualidade foram naturalizadas (ALMEIDA, 2004, p. 93).

Se "Isso deu início a uma tradição de um século na qual o anormal e homossexual foram apresentados como um enigma e o normal e heterossexual presumidos" (ibid., p. 66), é fácil perceber quais as linhas e conexões que antecedem a inauguração da transexualidade enquanto categoria também inventada.

Dessa vez, a invenção tem por objetivo central a manutenção da heterossexualidade, como podemos ver mediante as teses de Money e de suas intervenções cirúrgicas que visam à fabricação de corpos adequados para o ato sexual heteronormativo. 


\section{TTMEPARUS \\ REFLECTIONIS}

Volume, 13, n.2, Ano, 2017.

Compreendemos que realizar uma problematização da transexualidade implica uma tarefa substancial de desconstrução das noções e verdades arquitetadas em torno da sociedade heterocentrada e de suas normas produzidas a partir do ideal heterossexual.

Embora não queiramos recair em mais dicotomias, ou seja, heterossexualidade/transexualidade, não podemos deixar de evidenciar o fato de que toda a estranheza em relação ao que é considerado diferença se funda a partir de uma lógica decorrente de uma identidade tida como padrão e, portanto, desejada. E da depreciação daquelas pessoas que são consideradas como estranhas e anormais.

Com isso, também não queremos nos colocar em oposição à heterossexualidade, a qual se inclui entre uma das formas de se vivenciar uma política sexual e práticas sexuais. O que buscamos é uma equivalência para expressões de sexualidades distintas da heterossexual.

O que pretendemos é questionar, analisar as práticas e discursos que operam para manutenção e produção do sistema heterocentrado. Desestabilizar as naturalizações e essencialismo atribuídos aos corpos e aos papéis de gênero, ou seja, a forma como socialmente cada pessoa desempenha seu gênero. Denunciar as violências desempenhadas pelas dicotomias de gênero. Assim como a imposição e centralidade do pênis nas práticas sexuais, e a depreciação da totalidade dos corpos em alusão aos órgãos genitais como única garantia de satisfação orgástica nas práticas sexuais. Buscamos defender o uso de linguagens e vivências para práticas sexuais plurais, as quais possam circular, transitar por diferentes espaços sociais, institucionais e culturais. Em particular, pelos espaços escolares e contextos educacionais, dado seu caráter formativo e de necessário acolhimento das alteridades.

A filosofia de Beatriz Preciado nos inspira a pensar para além das dicotomias, e a desejar movimentos contínuos de contestação e subversão, assim como a utilizar as tecnologias a favor das resistências, e para o esboço de rotas de fugas capazes de produzir territórios potencializados para o exercício de vivências sexuais estrangeiras, inomináveis e plurais. Mediante sua proposta contrassexual, a defesa é por uma “... contraprodutividade, isto é, a produção de formas de prazer-saber alternativas à sexualidade moderna. [...] tecnologias de resistência, dito de outra maneira, como formas de contradisciplina sexual" (PRECIADO, 2014, p. 22). 


\section{TTMERARUS REFLECTIONIS}

Volume, 13, n.2, Ano, 2017.

Após percorrermos a trajetória da arquitetura conceitual da transexualidade, pudemos perceber que essa surge mediante um projeto político e tecnológico de sustentação do modelo hegemônico de feminilidade e masculinidade, o qual se constitui de modo a manter a lógica causal entre sexo-gênero-orientação sexual. O que está em questão é que a ordem heterocentrada se reafirma, a partir do sentido naturalizante do que se compreende por homem e mulher assignados pelo nascimento, assegurados pela inteligibilidade genital e biologizante, em detrimento do reconhecimento identitário dos sujeitos.

Quando nós, educadoras e educadores, nos propomos a adentrar nesse território político de produção das diferenças, e não nos ausentamos, ou silenciamos, perante as minúcias que tecem as multiplicidades de gêneros e sexuais, podemos atuar como protagonistas no enfrentamento do preconceito, discriminação e violência que permeia as diferentes instituições, como as instituições educativas, sejam formais ou não formais. Educadoras/es devem ser pioneiras/os em defesa das pessoas que são produzidas como abjetas, estranhas, e postas à margem do exercício dos direitos humanos essenciais, como o direito à educação de qualidade.

Devemos lembrar que a teia refinada que produz a transexualidade também incita pessoas transexuais a se evadirem dos ambientes de ensino, e as leva aos guetos de uma sociedade perversa e excludente. Uma educação que priorize as diferenças de gêneros e sexuais deve, primeiramente, conhecer a realidade da dimensão produtiva das homossexualidades, travestidades, lesbianidades, bissexualidades e transexualidades. $\mathrm{O}$ que poderá permitir ações educacionais potencializadoras perante as experiências de sujeitos que afirmam modos múltiplos do viver, seja em seus corpos, subjetividades, expressões de gênero, orientações sexuais, ou explorações sexuais circunstanciais ${ }^{7}$.

\section{Referências bibliográficas:}

ALMEIDA, Miguel Vale de. A teoria queer e a contestação da categoria 'género'. In: CASCAIS, António Fernando. Indisciplinar a teoria: estudos gays, lésbicos e queer. Fenda Edições, 2004, p.91-98.

BENTO, Berenice. A reinvenção do corpo: sexualidade e gênero na experiência transexual. Rio de Janeiro: Editora Garamond, 2006.

\footnotetext{
${ }^{7}$ Referimo-nos aqueles sujeitos que experimentam práticas não heterossexuais, ou transitam pelos gêneros, mas não, necessariamente, se reconhecem ou se nomeiam em categorias fixas.
} 
Volume, 13, n.2, Ano, 2017.

O que é transexualidade. São Paulo: Brasiliense, 2008.

O que pode uma teoria? estudos transviados e a despatologização das identidades trans. Revista Florestan, n. 2, p. 46, 2014.

BUTLER, Judith. Problemas de gênero: feminismo e subversão da identidade. Rio de Janeiro: Civilização Brasileira, 2010.

CASTEL, Pierre-Henri. Algumas reflexões para estabelecer a cronologia do "fenômeno transexual" (1910-1995). Revista Brasileira de História. São Paulo, v. 21, no 41, p. 77111. 2001.

FOUCAULT, Michel. A história da sexualidade 1: A vontade de saber. Rio de Janeiro: Graal, 2010.

GONÇALVES, Camila de Jesus Mello. Transexualidade e direitos humanos: $o$ reconhecimento da identidade de gênero entre os direitos da personalidade. Curitiba: Juruá, 2014.

KATZ, Jonathan Ned. A invenção da heterossexualidade. Rio de Janeiro: Ediouro, 1996.

LEITE JÚNIOR, Jorge. Nossos corpos também mudam. Sexo, gênero, e a invenção das categorias "travesti" e "transexual" no discurso cientifico. Tese (Doutorado em Ciências Sociais) - Programa de Pós-Graduação em Ciências Sociais da Pontifícia Universidade Católica de São Paulo. São Paulo: 2008.

PAMPLONA, Renata Silva. O kit anti-homofobia e os discursos sobre diversidade sexual. 2012. 147 f. Dissertação (Mestrado em Educação) - Programa de Pós-Graduação em Educação da Universidade Federal de São Carlos. São Carlos: 2012.

PAMPLONA, Renata Silva; DINIS, Nilson Fernandes. A moral do ressentimento e as práticas discriminatórias na diversidade sexual. Itinerarius Reflectionis, v. 8, n. 2, p. 120, 2013.

PRECIADO, Beatriz. Manifesto contrassexual. São Paulo: n-1 edições, 2014.

SOUZA, Edmacy Quirina. Crianças negras em escolas de "alma branca": um estudo sobre a diferença étnico-racial na educação infantil. 2016. 245 f. Tese (Doutorado em Educação) - Programa de Pós-Graduação em Educação da Universidade Federal de São Carlos. São Carlos: 2016. 


\section{ITHNERARS REFLECTIONIS \\ REVISTA ELETRÔNICA \\ DA GRADUAÇÃO/PÓS-GRADUAÇÃO EM EDUCAÇÃ O}

Volume, 13, n.2, Ano, 2017. 